\title{
Pre-resectional Radiofrequency Ablation as a Neoadjuvant in situ Tumor Vaccine
}

Fumito Ito ${ }^{1,2}$ and Sharon S Evans ${ }^{3^{*}}$

${ }^{1}$ Center for Immunotherapy, Roswell Park Cancer Institute, Buffalo, New York, USA

${ }^{2}$ Department of Surgical Oncology, Roswell Park Cancer Institute, Buffalo, New York, USA

${ }^{3}$ Department of Immunology, Roswell Park Cancer Institute, Buffalo, New York, USA

"Correspondence author: Sharon S Evans, Department of Immunology, Roswell Park Cancer Institute, Buffalo, NY 14263, USA, Tel: 716-845-3421; Fax: 716-845-1322; E-mail: sharon.evans@roswellpark.org

Received date: February 26, 2016; Accepted date: March 05, 2016; Published date: March 09, 2016

Copyright: (c) 2016 Ito F, et al. This is an open-access article distributed under the terms of the Creative Commons Attribution License, which permits unrestricted use, distribution, and reproduction in any medium, provided the original author and source are credited.

\section{Abstract}

A lack of effective immune response against cancer is one of the major risk factors for developing local recurrence and distant metastases after curative resectional surgery. Prior studies revealed that systemic antitumor immunity is elicited by radiofrequency ablation (RFA) of tumor lesions, which is mainly considered a palliative procedure for unresectable tumors or for inoperable patients. Recently, we discovered an oncological benefit that depends on the adaptive arm of the antitumor immune response when RFA is performed in a neoadjuvant setting prior to surgical resection in preclinical murine models.

\section{Short Communication}

Radiofrequency ablation (RFA) is increasingly being applied to a broad spectrum of solid malignancies. The principal application of this procedure has been for local tumor control as an alternative to surgical resection for unresectable tumors or for inoperable patients. Unlike surgical resection, however, the ablated tumor remains in situ and causes a robust inflammatory response.

Recently, accumulating data in preclinical and clinical studies have further identified an immunomodulatory benefit of RFA [1,2]. A highfrequency alternating current induces frictional heating, causing hyperthermic injury to ablated cells followed by coagulation necrosis. Dying tumor cells provide a source of tumor antigens that are taken up and presented to cognate $\mathrm{T}$ cells by dendritic cells (DC) [1]. Mechanical cell damage also induces strong upregulation of mRNA and/or protein levels of heat shock proteins and glycoprotein 96 as well as translocation of nuclear high-mobility group protein B1 (HMGB1) [3-5] into the cytoplasm of tumor cells. Release of these dangerassociated molecular pattern (DAMP) proteins into the extracellular space promotes DC maturation, thereby stimulating adaptive immunity culminating in the priming of tumor-specific $\mathrm{T}$ cells [6]. RFA also causes systemic inflammation associated with increased circulating levels of interleukin-1 $\beta$ (IL-1 $\beta$ ), IL-6, IL-8, and tumor necrosis factor- $\alpha$ (TNF- $\alpha)[1,7,8]$. In the peripheral or transitional zone adjacent to the central area of coagulative necrosis, infiltration by multiple immune effectors including neutrophils, macrophages, DC, NK cells, and $\mathrm{CD}^{+} \mathrm{T}$ cells has been reported [9-11]. Importantly, spontaneous regression of distant untreated tumors (abscopal effects) after the application of local ablative therapy has been reported in preclinical murine models and cancer patients although the mechanisms have been unclear [12-17]

Evidence for the immunostimulatory activities of RFA inspired us to evaluate the potential oncological benefits of RFA as a neoadjuvant procedure [18]. For these studies we reasoned that the immunomodulatory activity of RFA could be exploited for therapeutic benefit by performing RFA prior to surgical resection (pre-resectional
RFA). We tested this hypothesis in preclinical solid tumor models that represent highly immunogenic tumors (i.e., CT26 murine colon adenocarcinoma) versus poorly immunogenic tumors (B16.F10 melanoma) [19]. Of note, both these tumor systems are characterized by minimal infiltration by activated $\mathrm{CD}^{+} \mathrm{T}$ cell populations under baseline conditions [18-20]. In our proof-of-principle study [18], CT26 and B16.F10 tumor-bearing mice were treated by neoadjuvant RFA 7 days prior to resection to allow sufficient time for an adaptive immune response to be generated (Figure 1). Experimental procedures were performed so that there was a high incidence $(\geq 75 \%)$ of local recurrence with either monotherapy [18]. In contrast, pre-resectional RFA significantly delayed tumor growth and improved overall survival in $60-80 \%$ of tumor-bearing mice [18]. Findings that cure rates did not reach $100 \%$ suggest that pre-resectional RFA treatment tips a delicate balance between tumor escape and tumor elimination in established cancer nodules.

Several lines of evidence in our published study [18] supported a model in which the local and systemic benefit of pre-resectional RFA with respect to improved tumor control and survival is attributed to inducible immune protection rather than to the cytoreductive activity of RFA which could theoretically make tumors more amenable to complete surgical excision (Figure 1) [18]. In this regard, therapeutic efficacy was shown to be completely abrogated in immunodeficient mice that are genetically incapable of mounting an adaptive immune response, formally demonstrating the requirement for an intact immune system for the antitumor activity of RFA in a neoadjuvant setting. Infiltration of $\mathrm{CD}^{+} \mathrm{T}$ cells was significantly augmented not only in the transitional zone of ablated tumor, but also in distant tumors outside the treatment area and was associated with a significant increase in the ratio of $\mathrm{CD}^{+}$effector $\mathrm{T}$ cells-to- $\mathrm{CD} 4^{+} \mathrm{CD} 25^{+} \mathrm{FoxP}^{+}$ regulatory $\mathrm{T}$ cells (Treg) within the intratumoral microenvironment [18]. Notably, this increased $\mathrm{CD} 8^{+} \mathrm{T}$ cell effector:Treg ratio reflected overall improvement in intratumoral infiltration by $\mathrm{CD} 8^{+}$effector $\mathrm{T}$ cells whereas Treg localization at the treatment site was unchanged after RFA [18]. RFA treatment also did not alter infiltration by myeloid-derived suppressor cells (MDSCs) or M1 and M2 macrophages in ablated tumors or in peripheral lymphoid organs [18]. 


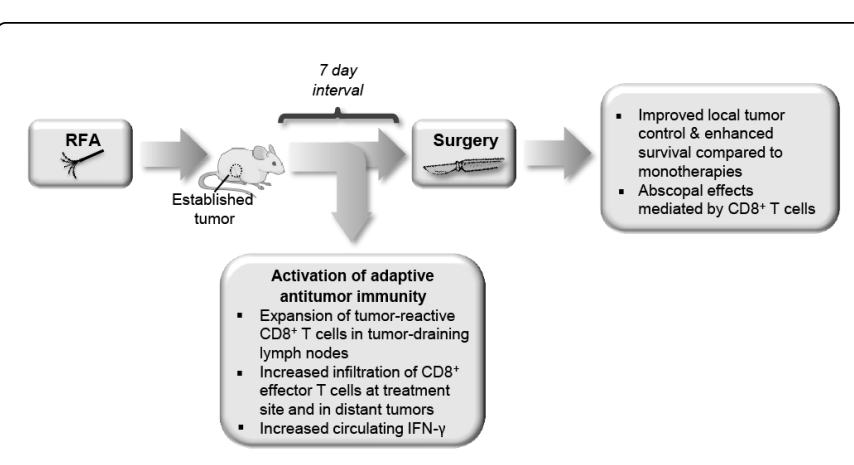

Figure 1: Experimental design for the use of RFA in a neoadjuvant setting in preclinical mouse tumor models [18]. Mice with established colorectal or melanoma tumors were treated with RFA for 1 minute. Seven days later mice underwent resection of ablated tumors. Pre-resectional RFA is proposed to promote activation and expansion of the pool of tumor-reactive cytotoxic $\mathrm{CD}^{+} \mathrm{T}$ cells in tumor-draining nodes. While the immunostimulatory effects of RFA alone do not protect against recurrence, when performed prior to excisional surgery RFA mobilizes cytotoxic $\mathrm{CD} 8^{+} \mathrm{T}$ cells to the local treatment site and remote metastatic sites, allowing them to execute their cytotoxic functions leading to improved tumor control and enhanced survival.

We further detected a significant increase in circulating interferon- $\gamma$ within 7 days after RFA treatment which is consistent with enhanced systemic immunity [18]. While we did not observe a change in total $\mathrm{CD}^{+} \mathrm{T}$ cell infiltration at treatment sites, an important outstanding question is whether the IFN- $\gamma$-producing $\mathrm{CD}^{+} \mathrm{T}$ cell subset contributes to the efficacy of pre-resectional RFA. A significant increase in antigen-driven accumulation of $\mathrm{CD}^{+} \mathrm{T}$ cells was further observed at the treatment site as well as in tumor-draining lymph nodes [18]. Notably, depletion of a single type of immune cell, the $\mathrm{CD}^{+} \mathrm{T}$ cell subset, abrogated the antitumor activity of pre-resectional RFA in distant tumors [18], thus demonstrating for the first time the requirement for $\mathrm{T}$ cell-based adaptive immunity in the abscopal effects of RFA.

Our findings indicate that RFA performed in a neoadjuvant setting could offer clinical benefits that might be superior to conventional neoadjuvant treatments. Several therapeutic modalities such as radiotherapy, chemotherapy, and/or targeted therapy have been used for the treatment of locally advanced and/or metastatic solid malignancies such as colorectal cancer liver metastases. These treatments, if performed in a neoadjuvant setting, can decrease the size of the tumor and thereby increase the possibility of obtaining negative margins at the time of surgery. However, these benefits have come at the cost of significant treatment-related toxicity. For example, chemotherapy prior to liver resection for colorectal cancer liver metastases can cause chemotherapy-associated steatohepatitis, vascular injury, and idiopathic noncirrhotic portal hypertension [21-23], which might increase morbidity or mortality after surgical resection. The duration of treatment varies depending on the regimen, but neoadjuvant chemotherapy with or without targeted therapy for colorectal liver metastases often takes weeks-to-months to complete, and not all the patients can tolerate the regimen. Thus, delaying surgery and allowing metastatic development in non-responsive tumors are potential shortcomings. Radiation therapy can also be used for neoadjuvant, adjuvant, or palliative purposes for several types of cancers. However, its efficacy is limited by the oxygenation status of tumors or sensitivity of tumor cells to radiation.

RFA can be performed as a minimally invasive procedure under radiological guidance without general anesthesia for a wide variety of tumors and, in contrast to conventional treatment modalities, it is not limited by intrinsic resistance of tumor targets to therapeutic intervention. Our data suggest that since it only takes a week for preresectional RFA to induce tumor-specific systemic immunity in solid murine tumor systems [18], it is not likely to delay definitive surgical resection in patients, with the caveat that humans mount a robust immune response in the same time-frame which remains to be documented. Moreover, a radiofrequency hepatic parenchymal transection device has been frequently used to control intraoperative hemorrhage during hepatic resection [24], suggesting pre-resectional RFA might decrease perioperative bleeding complications. Although systemic antitumor immunity induced by RFA alone is reportedly relatively weak, a number of recent studies suggest that there may be further promise of augmenting the $\mathrm{T}$ cell-mediated immune response by co-administration of immunological modifiers such as cytotoxic Tlymphocyte-associated protein 4 (CTLA-4) blockade [1,25]; depletion of regulatory T cells [25] or IL-2 [26,27]; or by administration of IL-7 and IL-15 [2], macrophage inflammatory protein-1a [28], heatshocked tumor cell lysate-pulsed dendritic cells [4], poxviral vaccines [17], or CpG-oligodeoxynucleotides [29,30].

Tumor immunogenicity is the dominant feature predicting response to immunotherapy, and primary and distant metastatic tumor sites may display different levels of immunogenicity [19]. Our preclinical studies showing that pre-resectional RFA is effective both in the highly immunogenic CT26 tumor as well as in the poorly immunogenic B16.F10 tumor suggest that this regimen could be broadly effective in tumor types with vastly different immune signatures. Given that RFA has already been approved for the treatment of multiple cancer types with minimal morbidity and mortality, our studies support the translational potential of pre-resectional RFA for patients who have high risk of local recurrence or distant metastases.

\section{Disclosures}

The authors have no conflicts of interest or financial interests to disclose.

\section{Grant Support}

Grant Number: NIH/NCI K08CA197966; NIH/NCI P30CA016056.

\section{References}

1. Den Brok MH, Sutmuller RP, van der Voort R, Bennink EJ, Figdor CG, et al. (2004) In situ tumor ablation creates an antigen source for the generation of antitumor immunity. Cancer Res 64: 4024-4029.

2. Chu KF, Dupuy DE (2014) Thermal ablation of tumours: biological mechanisms and advances in therapy. Nat Rev Cancer 14: 199-208.

3. Yang WL, Nair DG, Makizumi R, Gallos G, Ye X, et al. (2004) Heat shock protein 70 is induced in mouse human colon tumor xenografts after sublethal radiofrequency ablation. Ann Surg Oncol 11: 399-406.

4. Liu Q, Zhai B, Yang W, Yu LX, Dong W, et al. (2009) Abrogation of local cancer recurrence after radiofrequency ablation by dendritic cell-based hyperthermic tumor vaccine. Mol Ther 17: 2049-2057.

5. Rai R, Richardson C, Flecknell P, Robertson H, Burt A, et al. (2005) Study of apoptosis and heat shock protein (HSP) expression in hepatocytes following radiofrequency ablation (RFA). J Surg Res 129: 147-151. 
Citation: Ito F, Evans SS (2016) Pre-resectional Radiofrequency Ablation as a Neoadjuvant in situ Tumor Vaccine. J Vaccines Vaccin 7: 310. doi: $10.4172 / 2157-7560.1000310$

Page 3 of 3

6. Chen T, Guo J, Han C, Yang M, Cao X (2009) Heat shock protein 70, released from heat-stressed tumor cells, initiates antitumor immunity by inducing tumor cell chemokine production and activating dendritic cells via TLR4 pathway. J Immunol 182: 1449-1459.

7. Ali MY, Grimm CF, Ritter M, Mohr L, Allgaier HP, et al. (2005) Activation of dendritic cells by local ablation of hepatocellular carcinoma. J Hepatol 43: 817-822.

8. Fietta AM, Morosini M, Passadore I, Cascina A, Draghi P, et al. (2009) Systemic inflammatory response and downmodulation of peripheral CD25+Foxp3+ T-regulatory cells in patients undergoing radiofrequency thermal ablation for lung cancer. Hum Immunol 70: 477-486.

9. Dromi SA, Walsh MP, Herby S, Traughber B, Xie J, et al. (2009) Radiofrequency ablation induces antigen-presenting cell infiltration and amplification of weak tumor-induced immunity. Radiology 251: 58-66.

10. Wissniowski TT, Hänsler J, Neureiter D, Frieser M, Schaber S, et al. (2003) Activation of tumor-specific $\mathrm{T}$ lymphocytes by radio-frequency ablation of the VX2 hepatoma in rabbits. Cancer Res 63: 6496-6500.

11. Zerbini A, Pilli M, Laccabue D, Pelosi G, Molinari A, et al. (2010) Radiofrequency thermal ablation for hepatocellular carcinoma stimulates autologous NK-cell response. Gastroenterology. 138: 1931-1942.

12. Kim H, Park BK, Kim CK (2008) Spontaneous regression of pulmonary and adrenal metastases following percutaneous radiofrequency ablation of a recurrent renal cell carcinoma. Korean J Radiol 9: 470-472.

13. Sánchez-Ortiz RF, Tannir N, Ahrar K, Wood CG (2003) Spontaneous regression of pulmonary metastases from renal cell carcinoma after radio frequency ablation of primary tumor: an in situ tumor vaccine? J Urol 170: 178-179.

14. Soanes WA, Ablin RJ, Gonder MJ (1970) Remission of metastatic lesions following cryosurgery in prostatic cancer: immunologic considerations. J Urol 104: 154-159.

15. Eros de Bethlenfalva-Hora C, Mertens JC, Piguet AC, Kettenbach J, Schmitt J, et al. (2014) Radiofrequency ablation suppresses distant tumour growth in a novel rat model of multifocal hepatocellular carcinoma. Clinical science 126: 243-252.

16. Rao P, Escudier B, de Baere T (2011) Spontaneous regression of multiple pulmonary metastases after radiofrequency ablation of a single metastasis. Cardiovascular and interventional radiology 34: 424-430.

17. Gameiro SR, Higgins JP, Dreher MR, Woods DL, Reddy G, et al. (2013) Combination therapy with local radiofrequency ablation and systemic vaccine enhances antitumor immunity and mediates local and distal tumor regression. PLoS One 8: e70417.

18. Ito $\mathrm{F}, \mathrm{Ku} \mathrm{AW}$, Bucsek MJ, Muhitch JB, Vardam-Kaur T, et al. (2015) Immune Adjuvant Activity of Pre-Resectional Radiofrequency Ablation Protects against Local and Systemic Recurrence in Aggressive Murine Colorectal Cancer. PLoS One 10: e0143370.

19. Lechner MG, Karimi SS, Barry-Holson K, Angell TE, Murphy KA, et al. (2013) Immunogenicity of murine solid tumor models as a defining feature of in vivo behavior and response to immunotherapy. J Immunother 36: 477-489.

20. Fisher DT, Chen Q, Skitzki JJ, Muhitch JB, Zhou L, et al. (2011) IL-6 trans-signaling licenses mouse and human tumor microvascular gateways for trafficking of cytotoxic T cells. J Clin Invest 121: 3846-3859.

21. Hubert C, Sempoux C, Horsmans Y, Rahier J, Humblet Y, et al. (2007) Nodular regenerative hyperplasia: a deleterious consequence of chemotherapy for colorectal liver metastases?. Liver international : official journal of the International Association for the Study of the Liver 27: 938-943.

22. Aloia T, Sebagh M, Plasse M, Karam V, Levi F, et al. (2006) Liver histology and surgical outcomes after preoperative chemotherapy with fluorouracil plus oxaliplatin in colorectal cancer liver metastases. J Clin Oncol 24: 4983-4990.

23. Ward J, Guthrie JA, Sheridan MB, Boyes S, Smith JT, et al. (2008) Sinusoidal obstructive syndrome diagnosed with superparamagnetic iron oxide-enhanced magnetic resonance imaging in patients with chemotherapy-treated colorectal liver metastases. J Clin Oncol 26: 4304-4310.

24. Weber JC, Navarra G, Jiao LR, Nicholls JP, Jensen SL, et al. (2002) New technique for liver resection using heat coagulative necrosis. Ann Surg 236: 560-563.

25. Den Brok MH, Sutmuller RP, Nierkens S, Bennink EJ, Frielink C, et al (2006) Efficient loading of dendritic cells following cryo and radiofrequency ablation in combination with immune modulation induces anti-tumour immunity. British journal of cancer 95: 896-905.

26. Johnson EE, Yamane BH, Buhtoiarov IN, Lum HD, Rakhmilevich AL, et al. (2009) Radiofrequency ablation combined with KS-IL2 immunocytokine (EMD 273066) results in an enhanced antitumor effect against murine colon adenocarcinoma. Clin Cancer Res 15: 4875-4884.

27. Kroeze SG, Daenen LG, Nijkamp MW, Roodhart JM, de Gast GC, et al. (2012) Radio frequency ablation combined with interleukin-2 induces an antitumor immune response to renal cell carcinoma in a murine model. J Urol 188: 607-614.

28. Iida N, Nakamoto Y, Baba T, Nakagawa H, Mizukoshi E, et al. (2010) Antitumor effect after radiofrequency ablation of murine hepatoma is augmented by an active variant of CC Chemokine ligand 3/macrophage inflammatory protein-1alpha. Cancer research 70: 6556-6565.

29. Den Brok MH, Sutmuller RP, Nierkens S, Bennink EJ, Toonen LW, et al. (2006) Synergy between in situ cryoablation and TLR9 stimulation results in a highly effective in vivo dendritic cell vaccine. Cancer Res 66: 7285-7292.

30. Behm B, Di Fazio P, Michl P, Neureiter D, Kemmerling R, et al. (2016) Additive antitumour response to the rabbit VX2 hepatoma by combined radio frequency ablation and toll like receptor 9 stimulation. Gut 65: 134-143. 